Article

\title{
How Can an Image of Sustainability Be Trusted? The Inner World of Corporate Social Responsibility
}

\author{
Ruiqian Xu ${ }^{1, *}$, Dongning Yang ${ }^{2}$, Xin Chen ${ }^{3}$ \\ 1 National School of Development, Peking University, Beijing 100871, China \\ 2 Guanghua School of Management, Peking University, Beijing 100871, China \\ 3 Martin School of Public Policy and Administration, University of Kentucky, \\ Lexington, KY 40506, USA \\ * Correspondence: Ruiqian Xu, Email: xuruiqian@pku.edu.cn.
}

\begin{abstract}
Corporate social responsibility (CSR) is widespread in the commercial world, but companies often face suspicion regarding the latent motivation behind their CSR activities. How can firms make outside observers perceive their CSR as authentic and gain trust? Instead of focusing on CSR content and activities, we look into an organization's intrinsic sensemaking process of CSR. Identity orientation, legitimacy, and posture are identified as three important attributes that reflect firms' mental frame regarding CSR. We demonstrate type-by-type links among these sensemaking attributes and build configurations of CSR profiles to explore how these attributes work in combination to help firms gain trust from outside observers. Two scenario experiments are employed to test our hypotheses. The results indicate that observers' trust is high when these three attributes are perceived as consistently and coherently underlying firms' CSR activities. Specifically, when individual identity orientation is configured with pragmatic legitimacy and a defensive posture or when relational identity orientation is configured with moral legitimacy and a tentative posture, observers' trust can be enhanced.
\end{abstract}

KEYWORDS: corporate social responsibility; sensemaking process; trust; configurations

\section{G Open Access}

Received: 31 March 2020

Accepted: 15 November 2020

Published: 23 November 2020

Copyright $\odot 2020$ by the author(s). Licensee Hapres, London, United Kingdom. This is an open access article distributed under the terms and conditions of Creative Commons Attribution 4.0 International License.

\section{INTRODUCTION}

The strategic view of corporate social responsibility (CSR) emphasizes the benefits of CSR for a company's reputation, goodwill, and stakeholder support and hence the company's bottom-line performance [1,2]. However, such positive outcomes may be largely contingent on stakeholders' awareness and judgements of a company's CSR [3]. Companies worldwide are becoming increasingly active in publicizing their CSR work, but the disclosure of this work could be judged as ingratiating rather than as genuine manifestations of companies' intentions. As many instances of greenwashing have been exposed [4], companies often face suspicion that 
they are disseminating false or incomplete CSR information to mislead consumers and improve their image.

Despite the widespread scepticism towards firms' CSR publicity, there remains a dearth of research on how firms can communicate CSR more effectively [5]. Most researchers analyse CSR by focusing on organizational activities [6]. However, simply documenting activities or relying on CSR ratings is insufficient for explaining why some firms succeed in developing constructive relationships with stakeholders while others fail to do so, given the trend of rising homogeneity and near standardization in CSR reporting [7]. Beyond CSR publications or ratings, organizations' intrinsic values and motivations perceived by observers matter directly for observers' reactions and hence for organizational outcomes [8]. A more robust conceptual basis must be established to understand how observers perceive a firm's CSR as authentic.

There has been increasing interest in studying CSR based on the underlying mental frames of companies rather than simply analysing the content of CSR activities. Basu \& Palazzo (2008) proposed a sensemaking process as a lens through which CSR activities reveal the intrinsic character of a firm [9]. They identified cognitive, linguistic and conative processes that, respectively, imply "what firms think", "what firms say", and "how firms tend to behave" when they conduct CSR activities. Under such a sensemaking frame, we are able to reveal how an organization views the relationships between itself and its stakeholders and how stakeholders or observers at large perceive the organization through CSR and then form their attitudes and behavioural intentions towards the organization. Among the intrinsic characteristics of CSR, identity orientation, legitimacy, and posture are factors can potentially influence social acceptance and trust $[10,11]$. In their process model of sensemaking, Basu and Palazzo (2008) attributed a firm's identity orientation and legitimacy to its cognitive process and attributed posture to a firm's conative process [9]. Previous literature has mostly investigated these three sensemaking factors separately and has not considered their combined influence. Linking these factors and examining the configurations of sensemaking dimensions might provide a reliable basis for inferring the intrinsic nature of CSR engagement. It has been suggested that a consistent and coherent pattern of CSR would lead to the most favourable assessments and reactions from firm stakeholders [12,13].

We employ a configuration approach to explore how firms' intrinsic CSR characteristics combine to form a coherent CSR profile and influence observers' trust. First, we identify fine-grained links among identity orientation, legitimacy and posture, illustrating how these sensemaking dimensions can be mutually reinforcing in observers' perception. We then build configurations through, for example, a "triangular prism" of the sensemaking process and demonstrate how observers' trust can be enhanced under different configurations. Based on scenario experiments with observers, we find that trust is high when the three sensemaking attributes are perceived coherently and consistently in one configuration. 
Specifically, configuration with high degrees of individual identity orientation, pragmatic legitimacy, and defensive posture perceptions and configurations with high degrees of relational identity orientation, cognitive legitimacy and tentative posture perceptions can enhance trust.

\section{CSR AS A PROCESS OF SENSEMAKING}

Most researchers use content-based models to analyse CSR, focusing largely on inventories of CSR activities [6]. However, simply documenting CSR-related activities without understanding their precipitating causes is unlikely to reveal real differences among firms given the trend of rising homogeneity and standardization in CSR reporting.

Rather than focusing largely on the surface of CSR activities, an alternative description of CSR emerges from studying internal institutional determinants that might trigger or shape such activities in the first place. Basu and Palazzo (2008) study CSR based on intrinsic mental frames and define CSR as a sensemaking process that reflects a firm's view of what constitutes appropriate relationships with its stakeholders and the outside environment [9]. Through the lens of sensemaking, observers can extract an organization's intrinsic character from its CSR activities or discourses, and this perception then influences their judgement towards the firm. In their conceptual model to analyse CSR intrinsically, Basu and Palazzo (2008) divide the sensemaking process into three dimensions: cognitive, linguistic and conative processes [9]. The cognitive process implies "what firms think", especially how an organization thinks about its relationships with stakeholders and how it views the broader world. This process involves the type of identity orientation and legitimacy the organization aims to pursue. The linguistic process implies "what firms say", which involves the ways that firms explain their reasons for engaging in specific activities and how they go about sharing such explanations with others. The conative process implies "how firms tend to behave”, mainly involving the behavioural posture a firm adopts when facing the expectations, demands, or criticisms of others along with the commitment and consistency it shows in conducting activities that impinge on its perceived relationships.

Viewing CSR as derived from organizational sensemaking, observers can obtain an in-depth look into an organization's character from their perception of the tripartite sensemaking process. By observing and reading reports about an organization's CSR, observers gradually perceive how the organization thinks about its relationships with stakeholders and how it tends to behave with respect to the fulfillment and achievement of these relationships. In this article, we discuss the kinds of sensemaking processes that are most likely to forge trustworthiness perceived by an organization's stakeholders and other outside observers. Based on the tripartite sensemaking framework, we extract three dimensions (i.e., identity orientation, legitimacy and posture) that are likely to influence observers' trust according to previous research, and we diagnose which 
configurations are most conducive to building trust through CSR perceptions.

\section{Identity Orientation}

Identity answers the question "Who are we as an organization?" Researchers generally define organizational identity as members' shared perceptions of their organization's central, distinctive, and enduring qualities [14]. While identity simply focuses on the essence of an organization itself, the concept of "identity orientation" sheds light on the natural link between organizational identity and an organization's treatment of its stakeholders. Brickson (2007) proposed identity orientation as a construct that consists of participants' shared perceptions of what their organization is and how they associate with others, thereby driving motivation and behaviour [15]. This construct addresses the question "Who are we as an organization vis-à-vis our stakeholders?" Three types of organizational identity orientation are outlined by Brickson (2007) through a profoundly different perspective of reality, derived from deeply rooted and commonly held underlying assumptions about the nature of independence and interdependence between entities [15]. Individual identity orientation describes the extent to which organizations emphasize individual liberty and self-interest, and it refers to an organization's self-conception as a sole entity that is atomized and distinct from others. Relational identity orientation describes the extent to which organizations conceive themselves as being partners in relationships with their stakeholders. It corresponds to the self-conception of the organization as a dyadic inter-entity relationship partner possessing particularized bonds with specific stakeholders. Collectivistic identity orientation refers to the extent to which organizations believe that they are members of larger groups that go beyond stakeholders most relevant to their immediate business, possessing generalized ties with others. It refers to an organization's self-conception as a member of a larger group with generalized ties to other stakeholders in that group [9,15]. Our conceptualizations of identity orientation perceptions build on these distinctions.

\section{Organizational Legitimacy}

The perceived need to gain acceptance in society, especially among stakeholders, leads organizations to strive for compliance with "some socially constructed system of norms, values, beliefs, and definitions" [16]. Organizations seek legitimacy to pursue continuity and credibility as well as passive and active support. Three approaches can be differentiated: pragmatic, cognitive, and moral legitimacy. Pragmatic legitimacy rests on the benefits for stakeholders that are perceived to spring from an organization's existence or behaviour. Achieving pragmatic legitimacy hinges on an organization's ability to convince its stakeholders of the usefulness of its decisions, products, or processes. Moral legitimacy rests 
on judgements about whether an activity conducted by a firm promotes societal welfare and is "the right thing to do" in accordance with observers' socially constructed value system. Under conditions of extreme uncertainty brought about by fundamental social changes, organizations might strive to achieve moral legitimacy by co-creating acceptable norms of behaviour with relevant stakeholders. In seeking cognitive legitimacy, a firm aligns its actions to be congruent with perceived societal expectations. Cognitive legitimacy emerges when the societal context regards a firm's CSR output, procedures and structures as right and necessary based on taken-for-granted assumptions. For example, if a firm claims to address a broadly shared social or environmental issue, such as global warming, or rallies resources with renowned institutions to engage in high-profile activism, it is likely to gain wide acceptance at subconscious level.

\section{Interaction between Identity Orientation and Legitimacy}

Before we build configurations based on the whole sensemaking process, we argue that there are interactive relationships between identity orientation and legitimacy. The interplay between identity orientation and legitimacy can be instrumental in understanding the interface between organizations and their environments [17] and can help us build sensemaking configurations. Several authors have already noted the salience of such interactions. For example, Deephouse (1999) explained that by acquiring a common identity, a firm gains legitimacy, whereas by acquiring a distinct identity, a firm faces less competition [18]. He and Baruch (2010) empirically demonstrated that both identity orientation and legitimacy should be considered in analysing an organization's reactions and responses to external change [19]. Gillespie, Dietz, and Lockey (2014) argued that establishing a positive organizational identity speed ups and increases the likelihood that an organization restores stakeholders' perceptions of its legitimacy [20].

Based on these earlier arguments, we assert that identity orientation and legitimacy actively interact when stakeholders perceive organizations' sensemaking process. Concrete characteristics of identity expressions may affect stakeholders' perception of a company, and by knowing exactly "who a company is", stakeholders can form or change their cognition on "why the company exists". When organizations expose their CSR information through their activities or reports, they can enhance or damage certain types of legitimacy in observers' perception along with another particular type of identity orientation.

\section{HYPOTHESES: MATCHING PERCEIVED IDENTITY ORIENTATION TO PERCEIVED LEGITIMACY}

In this section, we outline three relationships matching observers' perceived identity orientation and legitimacy. By conveying the types of identity orientation an organization makes sense of through CSR, 
observers focus organizations' legitimacy in specific directions, where legitimacy information is the most valid indicator of identity perceptions. Although we posit that there are relationships between one particular type of identity orientation and another corresponding type of legitimacy, we do not suggest that people who primarily monitor one type of organizational legitimacy are wholly unconcerned with other types.

\section{Individual Identity Orientation Matched with Pragmatic Legitimacy}

We hypothesize that individual identity orientation signals the importance of pragmatic organizational legitimacy more than relational or collectivistic identity orientations do. In institutional theory, pragmatic legitimacy captures the degree to which an organization represents its constituents' self-interests or provides them with favourable exchanges relative to alternative forms or structures $[16,21,22]$. Organizations that emphasize individual identity orientation care most about whether they are characterized as individual and independent of others. They emphasize that they are "the best in the business" based on individual liberty and self-interest, building on the notion that they are an "atomized" entity that is distinct and separate from others. Therefore, the perceived individual identity of such firms is more likely to persuade key stakeholders, as well as the wider public, of the usefulness of these firms' output, procedures, structures and leadership behaviour [21]. Stakeholders and the public ascribe legitimacy to such corporations as long as they perceive that they will benefit from these corporations' activities. Thus, we contend that when stakeholders perceive that a firm has an individual identity orientation, they tend to perceive more pragmatic legitimacy because they tend to be more convinced of the usefulness of the firm's decisions, products, or processes [16].

Hypothesis 1. Pragmatic legitimacy is more positively affected by observers' perception of a firm's individual identity orientation than by their perceptions of a firm's relational or collectivistic identity orientations.

\section{Relational Identity Orientation Matched with Moral Legitimacy}

We next hypothesize that relational identity orientation signals the importance of a firm's moral organizational legitimacy more than pragmatic or collectivistic identity orientations do. Organizations that emphasize their relational identity orientation care most about whether their CSR is characterized as relative to and connective with others. They emphasize themselves as "the trusted partner" in relationships with their stakeholders, building on a "connected" entity that is related to specific others. In institutional theory, moral legitimacy is associated with the evaluation of an organization as beneficial to an evaluator's social group or the whole society [23]. Under conditions of extreme uncertainty brought about by fundamental social changes, organizations might strive to achieve moral legitimacy by co-creating acceptable norms of behaviour 
with relevant stakeholders [9]. Calton and Payne (2003) also identified "relational responsibility" in stakeholders as a way to engage in collaborative search for social legitimacy through a variety of approaches [24]. Thus, we contend that stakeholders who perceive that a firm has a relational identity orientation tend to perceive more moral legitimacy.

Hypothesis 2. A firm's moral legitimacy is more positively affected by observers' perceptions of the firm's relational identity orientation than by their perceptions of the firm's individual or collectivistic identity orientations.

\section{Collectivistic Identity Orientation Matched with Cognitive Legitimacy}

Last, we hypothesize that collectivistic identity orientation signals the importance of cognitive organizational legitimacy more than individual or relational identity orientations do. Organizations that emphasize their collectivistic identity orientation care most about whether their CSR is characterized as collective with respect to others. The expressive characteristic that managers articulate although their CSR reports is how their organization's identity is collective. These organizations define themselves in universal terms such as "we believe in eliminating poverty" or "we strive for a sustainable earth" [9]. Cognitive legitimacy is based upon the idea of a nationally bound society with a national governance system and a homogeneous cultural background of shared norms, values and beliefs [16]. The common assumption of firms with both collectivistic identity orientation and cognitive legitimacy is that in engaging in CSR activities, these firms selectively take a decontextualized view of relationships and choose to address a widely perceived social or an environmental issue. A collectivistic entity tends to signal to observers that it serves as a natural way to affect collective actions, which is consistent with the taken-for-granted assumption of building cognitive legitimacy. In addition, both concepts operate mainly at the subconscious level, making it difficult for a corporation to directly and strategically influence and manipulate perceptions. Thus, in our context, we hypothesize that stakeholders who perceive that a firm has a collectivistic identity orientation tend to perceive more cognitive legitimacy.

Hypothesis 3. Cognitive legitimacy is more positively affected by observers' perceptions of a firm's identity orientation than by their perceptions of a firm's individual or relational identity orientations.

\section{TRUST ASSOCIATED WITH IDENTITY ORIENTATION, LEGITIMACY AND POSTURE}

Trust is "the confident, positive expectations regarding a trustee's conduct, motives, and intentions in situations entailing risk" [25]. Gaining and maintaining the trust is essential in CSR activities. Questioning of the motives for implementing CSR, and perceptions of corporate hypocrisy in 
CSR communications, will drive negative reactions to its CSR activities [26]. Numerous theorists have implied that organizational identity or identity orientation is a fundamental intrinsic factor that forms stakeholders' attitudes or judgements towards a firm. Whetten (2006) argues that when facing an organizational crisis, an organization's identity is the most relevant factor, and potentially the only salient factor, altering the collective understanding of "who we are as an organization" [27]. Building identity orientation is a significant trust-eliciting mechanism. Trust is formed based on identification with another party's motivation and behaviour, where parties effectively understand and appreciate one another's wants and know that their interests will be met in the long run. Legitimacy is also associated with trust as a cognitive sensemaking factor. Legitimate organizations are more likely to be perceived by stakeholders as trustworthy [16]. By contrast, organizations with fragile legitimacy run the risk of being perceived as unnecessary or irrational, which could harm social trust [28].

Through the cognitive sensemaking dimension, identity orientation and legitimacy can potentially influence social acceptance and trust, allowing observers to make sense of "what firms think". However, trust comes not only from what one thinks but also from what one is going to do based on cognitive constructs. Trust can be enhanced depending on whether a firm does what it says it is going to do [29]. Thus, along with considering the cognitive sensemaking dimension involving identity and legitimacy, we consider posture as another factor associated with trust, reflecting "how firms tend to behave".

The responsive posture of an organization with respect to the expectations, demands, or criticisms of others has been viewed as a key behavioural disposition [30]. Three dominant types of posture can be derived from the literature: defensive, tentative, and open. In being defensive, an organization accepts no feedback from others, presumes it is always right in terms of its decisions, and insulates itself from alternative sources of inputs. An organization might be tentative with respect to its posture towards others as a result of its inexperience with an issue or its lack of appropriate tools to devise solutions, causing it to be uncertain regarding the consequences of its actions. By contrast, an open posture is oriented towards learning that is based on the organization's willingness to listen and respond to alternative perspectives offered by others [31].

\section{CONFIGURATIONS OF THE PERCEIVED SENSEMAKING PROCESS}

Researchers typically investigate only one of these three contextual factors (identity orientation, legitimacy, or posture) without considering the others. What has been lacking is a systematic consideration of whether these factors affect the extent of social trust independently or in combination. Basu and Palazzo (2008) suggested that examining configurations of sensemaking dimensions might provide a reliable basis 
for inferring the nature of authentic CSR engagement instead of evaluating activity inventories [9]. If specific combinations of cognitive and conative features were found in certain firms but not in others, they would likely provide a reliable indication of these firms' CSR performance and increase social trust. The empirical agenda for CSR research could then involve investigating whether or not firms that display, for example, an individualistic identity orientation also tend to rely on pragmatic legitimacy and have a defensive posture to generate a significant influence on their CSR performance and social acceptance.

We configure these three dimensions under the sensemaking process and relate them to an organizational outcome (trust) from observers' perception. We believe that studies of such configurations can resolve some of the extant theoretical and empirical contradictions. When observers match legitimacy perceptions with identity orientation perceptions, the interactive effect along with perceived posture enhances trust. We argue that this occurs because people who are able to triangulate related identity orientation, legitimacy, and posture form a highly coherent perception of a particular organization. As a result, they experience high levels of trust because they are confident that the organization in question is providing them real and relevant information to build their perception of the organization.

We develop three hypotheses by supplementing the relationships predicted in Hypotheses 1-3 regarding the relationships between trust and perceived corporate traits from the CSR sensemaking process. The general framework is shown in Figure 1. Although we do not consider all possible combinations of types of identity orientation, legitimacy, and posture, these hypotheses provide an initial theoretical rationale for considering sensemaking configurations.

The first configuration involves perceived high levels of individual identity orientation, pragmatic legitimacy, and defensive posture. In keeping with Hypothesis 1, individual identity orientation signals the importance of pragmatic legitimacy. Combining these two cognitive sensemaking dimensions, organizations are perceived to cognize themselves as "atomized", "competitive" and "pursuing strong self-interest" $[15,16]$. With such a perception, observers subconsciously suppose that these organizations firmly adhere to their own perspectives when they face criticisms or challenges since these companies are so confident in their own activities. Thus, we propose that perceived individual identity orientation, pragmatic legitimacy, and defensive posture are combined in one configuration, and this consistency can lead to high trust among observers of the firm's sensemaking process.

Hypothesis 4. A three-way interaction of individual identity orientation, pragmatic legitimacy, and defensive posture predicts observers' trust. Specifically, a consistent configuration with high degrees of individual identity orientation, pragmatic legitimacy, and defensive posture perceptions can build the highest trust compared to other configurations. 


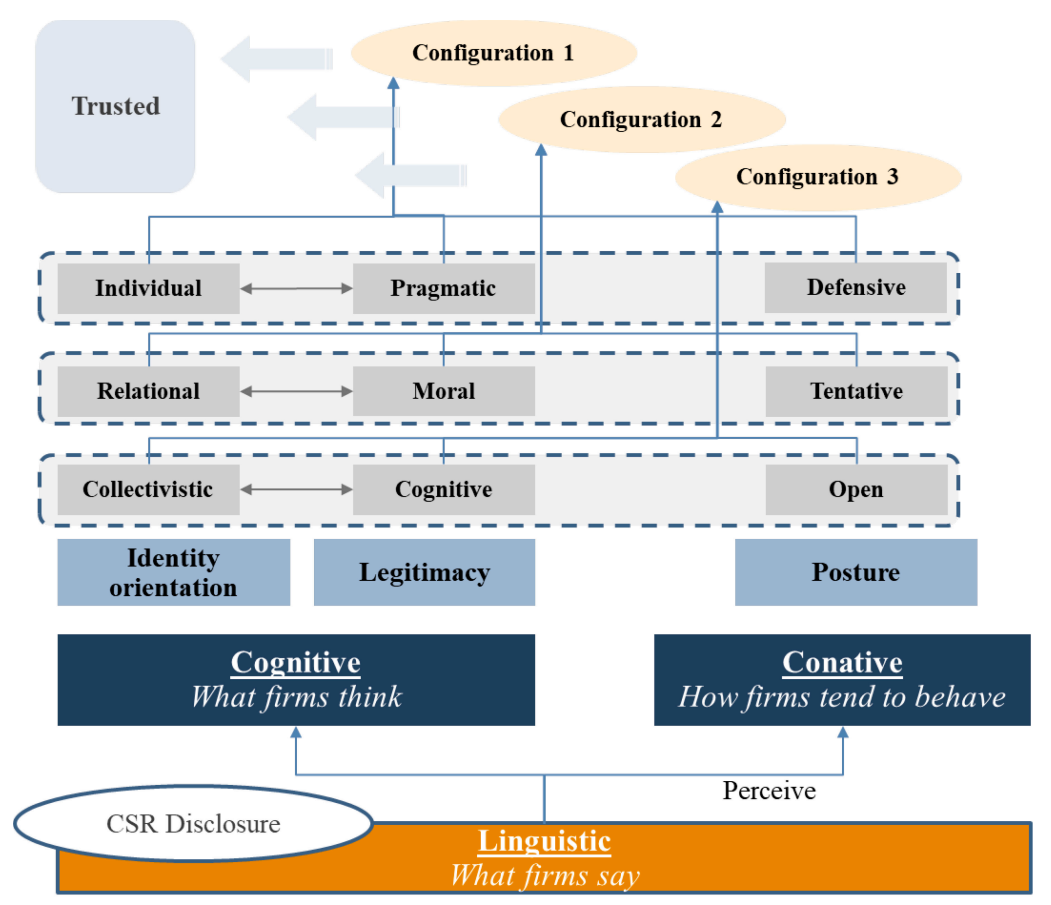

Figure 1. Sensemaking configurations and observers' trust.

The second configuration involves perceived high levels of relational identity orientation, moral legitimacy, and tentative posture. In keeping with Hypothesis 2, relational identity orientation signals the importance of moral legitimacy. Combining these two cognitive sensemaking dimensions, organizations are perceived to cognize themselves as a "trusted partner" and as "doing the right thing" in a way that is consistent with influential groups and social norms $[9,16]$. With such a perception, observers subconsciously suppose that those companies are apt to be sensitive to the opinions of their closely related stakeholders, such as suppliers and consumers, and display both established patterns of behaviour (i.e., those incurring criticism among broader stakeholders) and new behaviours directed at redressing misdeeds required by their close partners. Such inclusive attitude towards stakeholder voices is likely to be perceived as behavioural adherence to the vision of relational CSR, where the firm is oriented as a "connected" entity and engaged in collaborative search for social legitimacy. Thus, we propose that relational identity orientation, moral legitimacy, and tentative posture are combined in one configuration, and this consistency can enhance trust among observers of the firm's sensemaking process.

Hypothesis 5. A three-way interaction of relational identity orientation, tentative posture, and cognitive legitimacy predicts observers' trust. Specifically, a consistent configuration with high degrees of relational identity orientation, tentative posture, and cognitive legitimacy perceptions can build the highest trust compared to other configurations.

The third and last configuration involves perceived high levels of collectivistic identity orientation, cognitive legitimacy, and open posture. 
In keeping with Hypothesis 3, collectivistic identity orientation signals the importance of cognitive legitimacy. Combining these two cognitive sensemaking dimensions, organizations are perceived to cognize themselves as "collaborative", "inevitable" and "understandable" under widely shared social norms, values and beliefs [16,21]. With such a perception, observers subconsciously suppose that such companies are willing to listen and respond to alternative perspectives offered by crowds at large; they are open to sharing their perception of the issue with others and to debating and discussing the nature of both internal and external issues. Thus, we propose that collectivistic identity orientation, cognitive legitimacy, and open posture are combined in one configuration, and such consistency can help build trust among observers of a firm's sensemaking process.

Hypothesis 6. A three-way interaction of collectivistic identity orientation, cognitive legitimacy, and open posture predicts observers' trust. Specifically, a consistent configuration with high degrees of collectivistic identity orientation, cognitive legitimacy, and open posture perceptions can build the highest trust compared to other configurations.

Two empirical studies were employed to test the hypotheses. We first used a scenario study (Study1) to examine the type-by-type relationships between identity orientation and legitimacy that we outline in Hypotheses 1-3. We then administered a survey (Study2), additionally involving the judgement of companies' posture and observers' trust, to test Hypotheses 4-6.

\section{STUDY1: METHODS}

\section{Participants}

We employed a scenario study through both online and offline channels. We conducted an online survey by a self-designed administration system and sent a total of 150 personal invitations to nationwide respondents. Participants included professors from academic institutions who had lectured on CSR as well as managers and their subordinates who served in organizations that specialized in editing and evaluating CSR reports. A total of 87 individuals completed our online survey. In addition, we conducted offline surveys on 76 MBA students who had attended CSR classes. These participants were employed in a variety of industries with an average of 6.5 years of working experience. In total, our study included 163 participants, of whom 48 were engaged in the individual scenario, 70 were engaged in the relational scenario, and 45 were engaged in the collectivistic scenario.

\section{Procedures}

All respondents were first provided the following prompt: "You are going to read a description of a job in the RATE, a reputable corporation 
for consulting. Imagine that this is your job and picture yourself in this context”. Participants were then exposed to one of three scenarios that manipulated the identity information conveyed through the firm's CSR report, reflecting how the firm cognized itself and its relationships with its stakeholders [15]. The individual identity orientation scenario emphasized individual liberty and self-interest, involving statements such as "We are the most profitable corporation in the industry" and "Our organization is unique and we don't let competition stand in our way". The relational identity orientation scenario emphasized the firm being a partner in relationships with its stakeholders, using statements such as "Our organization is nurturing and cares deeply about partners" and "We endeavor to provide best service for our clients". The collectivistic identity orientation scenario focused on the firm being aggregated with others and treating them as "public citizens", with statements such as "Our organization is a benefit to the whole of the earth" and "We contribute to eliminating poverty from society".

Participants were then instructed to evaluate the firm mentioned in the report and to answer questions. They completed the 15 perceived managerial identity organization items described below using a Likert rating scale ranging from 1, "strongly disagree", to 7, "strongly agree". Finally, we asked respondents to report on the extent to which they agreed that the described firm was engaged in pragmatic, cognitive, or moral organizational legitimacy using the same seven-point scales for the 15 organizational legitimacy items described below.

\section{Measures}

Perceived identity orientation. To evaluate individuals' interpretations of identity orientations they encounter, we derived measures of perceived individual, relational, and collectivistic identity orientations from Brickson (2007) [15]. We generated three five-item scales that described the extent to which individuals perceived that an organization emphasized the particular performance and success criteria associated with each identity orientation. We obtained Cronbach's alpha coefficients of 0.67 for the five-item scale of individual identity orientation, 0.87 for the five-item scale of relational identity orientation, and .68 for the five-item scale of collectivistic identity orientation.

Perceived Legitimacy. We derived items that described the extent to which organizations were perceived to achieve particular types of legitimacy. To accomplish this, we reworded perceived legitimacy items from Suchman (1995) and Palazzo and Scherer (2006) [16,32]. This rewording process resulted in five-item pragmatic, cognitive, and moral legitimacy scales. We obtained Cronbach's alpha coefficient values of 0.70 for pragmatic legitimacy, 0.72 for cognitive legitimacy, and 0.65 for moral legitimacy. 


\section{Analysis}

We checked our manipulations using paired $t$-tests and found that individuals in the individualistic scenario condition maintained significantly higher individual identity orientation perceptions than either relational or collectivistic identity perceptions (mean difference with perceived relational identity orientation $=1.26, p<0.01$; with perceived collectivistic identity orientation $=1.02, p<0.01$ ). Individuals in the relational scenario condition had significantly higher relational identity orientation perceptions than either individual or collectivistic identity orientation perceptions (mean difference with perceived individual identity orientation $=0.92, p<0.00$; with perceived collectivistic identity orientation $=1.03, p<0.01$ ); and individuals in the collectivistic scenario condition maintained significantly higher collectivistic identity orientation perceptions than either individual or collectivistic identity perceptions (mean difference with perceived individual identity orientation $=1.31, p<0.01$; with perceived collectivistic identity orientation $=1.01, p<0.01$ ).

We ran ordinary least squares (OLS) regression analyses of each type of organizational legitimacy using our combined data with the three perceived identity orientation scales as independent variables in each analysis to see if the effects of perceived identity orientation were consistent with the effects produced by our scenarios. Since individuals might perceive organizational legitimacy for reasons besides their identity orientation perceptions, we controlled for an individual's propensity to monitor multiple types of organizational legitimacy by including the forms of organizational legitimacy that were not being predicted in both sets of analyses.

\section{STUDY1: RESULTS}

Descriptive statistics and correlations are presented in Table 1.

Table 1. Descriptive statistics and correlations among variables.

\begin{tabular}{|c|c|c|c|c|c|c|c|c|c|c|}
\hline Variables & Mean & s.d. & 1 & 2 & 3 & 4 & 5 & 6 & 7 & 8 \\
\hline 1.Individual scenario & 48 & n.a. & & & & & & & & \\
\hline 2.Relational scenario & 70 & n.a. & & & & & & & & \\
\hline 3.Collective scenario & 45 & n.a. & & & & & & & & \\
\hline 4.Individual identity & 4.71 & 1.28 & $0.36 * *$ & 0.02 & $-0.39 * *$ & & & & & \\
\hline 5.Relational identity & 4.82 & 1.58 & $-2.67 * *$ & $0.47^{* *}$ & $-0.25 * *$ & $0.20^{* *}$ & & & & \\
\hline 6.Collectivistic identity & 4.71 & 1.25 & $-0.16 *$ & -0.06 & $0.23 * *$ & 0.01 & $0.32 * *$ & & & \\
\hline 7.Pragmatic legitimacy & 4.93 & 1.07 & $0.23^{* *}$ & -0.02 & $-0.22 * *$ & $0.55^{* *}$ & $0.36 * *$ & $0.17^{*}$ & & \\
\hline 8.Cognitive legitimacy & 4.80 & 1.17 & -0.14 & $0.24^{* *}$ & -0.12 & $0.24^{* *}$ & $0.70 * *$ & $0.38 * *$ & $0.51 * *$ & \\
\hline 9. Moral legitimacy & 4.50 & 1.14 & $-0.34^{* *}$ & 0.13 & $0.21^{* *}$ & -0.14 & $0.41 *^{*}$ & $0.51^{* *}$ & $0.18 *$ & $0.53 * *$ \\
\hline
\end{tabular}

${ }^{*} p<0.05 ; * * p<0.01$; Two-tailed tests. 


\section{Testing of Hypotheses 1-3}

The results of our OLS regression analyses of the effects of the perceived identity organization scales on the organizational legitimacy variables (reported in Table 2) provide support for Hypotheses 1-3. In analyses when we controlled the levels of cognitive and moral legitimacy, perceived individualistic identity orientation is significantly related to pragmatic legitimacy ( $\beta=0.66, p<0.01$ ), whereas perceived relational identity orientation and collectivistic identity orientation are not so related to pragmatic legitimacy, supporting Hypothesis 1. When controlling the levels of pragmatic and cognitive organizational legitimacy, we found that perceived relational identity orientation significantly affects moral organizational legitimacy ( $\beta=0.42, p<0.01$ ), but perceived individualistic does not have a significant effect, and perceived collectivistic identity orientation has a marginal significant effect $(\beta=0.16$, $p<0.05$ ), partially supporting Hypothesis 2 . In our evaluation of cognitive organizational legitimacy, while controlling the levels of pragmatic and moral organizational legitimacy, we found that perceived collectivistic identity orientation exerted a significant effect $(\beta=0.27, p<0.01)$, but perceived relational identity orientation does not have a significant effect, and perceived individualistic identity orientation has a significant but negative effect $(\beta=-0.33, p<0.01)$, by which hypothesis 3 is also supported.

Table 2. Results of Regression Analyses of the effects of Perceived Identity Orientation on Perceived legitimacy $(n=163)^{\text {a }}$.

\begin{tabular}{lccc}
\hline Variables & Pragmatic Legitimacy & Moral Legitimacy & Collective Legitimacy \\
\hline Individual identity & $0.61^{* * *}$ & 0.05 & $-0.33^{* *}$ \\
Relational identity & -0.00 & $0.42^{* * *}$ & -0.22 \\
Collectivistic identity & 0.02 & $0.16^{*}$ & $0.27^{* *}$ \\
Pragmatic legitimacy & & $0.38^{* * *}$ & 0.14 \\
Moral legitimacy & $0.39^{*}$ & & $0.66^{* * *}$ \\
Cognitive legitimacy & -0.01 & 0.01 & \\
\multicolumn{1}{c}{$R^{2}$} & $0.44^{* * *}$ & $0.68^{* * *}$ & $0.54^{* * *}$ \\
\hline
\end{tabular}

${ }^{a}$ Reported values are standardized regression coefficients. ${ }^{*} p<0.05 ;{ }^{* *} p<0.01 ;{ }^{* * *} p<0.001$

\section{STUDY1: DISCUSSION}

The results of our scenario study strongly support our hypotheses stating that organizations' pragmatic legitimacy is associated with individualistic identity orientation; their moral legitimacy is associated with relational identity orientation; and their cognitive legitimacy is associated with collectivistic identity orientation. These relationships are all stronger than are those between each types of legitimacy and the other types of identity orientation. Promoting both related types of identity orientation and legitimacy can be mutually reinforcing, and based on these type-by-type links, we can then build isomorphic configurations and conduct further analysis in Study2. 


\section{STUDY2: METHODS}

To extend our analyses to a field sample and address the limitations of Study1 by including judgement of the behavioural disposition (i.e., perceived posture) of the organizations in our analyses, we evaluated Hypotheses 4-6 using a survey study.

\section{Participants}

We collected our data from MBA students who had taken CSR-related courses. We distributed CSR reports randomly and sent 352 surveys in three waves during a discussion class. Of the students who received the surveys, 350 completed it. Participants were employed in a variety of different industries, the most common being finance (32\%), IT or electronic communication (26\%), and manufacturing (5\%). Twenty-nine percent of Study2 participants were female; participants had an average age of 30.9 years and an average of 7.1 years of working experience.

\section{Procedures}

We instructed Study2 respondents as follows: All respondents were first asked to read the same CSR report of a firm that involved narratives about the company and its CSR-related activities, conveying how the firm recognized itself and tended to behave when interacting with its stakeholders and the environment at large. After a 15-minute interval, we sent them another questionnaire with the instruction "Please answer the following questions about the organization based on the report you have read" on the first line. Respondents rated each item on a scale ranging from 1 , "strongly disagree", to 7 , "strongly agree".

\section{Constructs}

Perceived Organizational Posture. In addition to including the perceived identity orientation and legitimacy scales used in Study1, we included measures of perceived responsive posture in the analysis to test the effects on trust predicted in Hypotheses 4-6. We adapted five defensive organizational posture items used by Staw, Sandelands and Dutton (1981) [33]; this scale had a Cronbach's alpha of .76. Our tentative justice measure utilized five items [21,31]; this scale had a Cronbach's alpha of 0.57. Our open posture measure utilized the six items (reflecting greater openness and a willingness to engage with the organization's critics) based on the transformation of posture used by Zadek (2004) [34]; this scale had a Cronbach's alpha of 0.82 .

Trust. Our measure of trust comprised fifteen items from Colquitt and Rodell's (2011) longitudinal analysis integrating the justice, trust, and trustworthiness perceived by supervisors regarding firms' CSR activities [25]. To generalize the applicability of the items across organizational trust systems, we also modified each item slightly to capture respondents' objective perceptions of "the organization" rather than the "supervisor" 
(e.g., "You suppose that the organization is very capable of performing social responsibility consistent with its commitment”). The scale assessed the perceived ability, benevolence, and integrity of an organization and the credibility of the report, which attained a Cronbach's alpha of 0.93 .

\section{Analysis}

To test Hypotheses 4-6, we examined the effects produced by interactions of identity orientation, legitimacy, and responsive posture on trust (standardized) using hierarchical regression analyses. The hierarchical approach is appropriate when analyzing multiplicative terms in regression analysis or, more generally, when analyzing highly correlated independent variables [35].

Trust was regressed in steps on (1) the control variables which involve all the alternative forms of identity orientation, organizational legitimacy, and posture, (2) focal independent variables estimating the main effects, (3) all two-way interactions between independent variables, and (4) the related three-way interaction of identity orientation, organizational legitimacy, and posture. In each step of the hierarchical analysis, the next higher order of interaction is added (two-way and three-way interactions, respectively), and incremental $\mathrm{R}^{2}$ and $\mathrm{F}$ tests of statistical significance are evaluated. An interaction effect exists if, and only if, the interaction term gives a significant contribution over and above the direct effects of the independent variables.

\section{STUDY2: RESULTS}

The descriptive Statistics of all variables are shown in Table 3.

Table 3. Descriptive Statistics and Correlations among Variables.

\begin{tabular}{|c|c|c|c|c|c|c|c|c|c|c|c|}
\hline Variables & Mean & s.d. & 1 & 2 & 3 & 4 & 5 & 6 & 7 & 8 & 9 \\
\hline 1. Trust & 5.17 & 1.01 & & & & & & & & & \\
\hline 2. Individual identity & 5.17 & 1.03 & $0.51 * *$ & & & & & & & & \\
\hline 3. Relational identity & 5.02 & 1.03 & $0.41 * *$ & $0.56 * *$ & & & & & & & \\
\hline 4. Collectivistic identity & 4.95 & 1.02 & $0.49 * *$ & $0.59 * *$ & $0.65 * *$ & & & & & & \\
\hline 5. Pragmatic legitimacy & 4.09 & 0.88 & $0.47 * *$ & $0.57 * *$ & $0.59 * *$ & $0.57^{* *}$ & & & & & \\
\hline 6. Moral legitimacy & 5.13 & 0.94 & $0.53 * *$ & $0.56 * *$ & $0.62 * *$ & $0.66^{* *}$ & $0.71^{* *}$ & & & & \\
\hline 7. Cognitive legitimacy & 4.82 & 0.92 & $0.50 * *$ & $0.50 * *$ & $0.57^{* *}$ & $0.64 * *$ & $0.59 * *$ & $0.68 * *$ & & & \\
\hline 8. Defensive Posture & 4.35 & 1.11 & 0.06 & $0.13 *$ & $0.24 * *$ & 0.08 & $0.31 * *$ & 0.11 & $0.13 *$ & & \\
\hline 9. Tentative Posture & 4.50 & 0.87 & $0.23 * *$ & $0.22 * *$ & $0.37 * *$ & $0.28 * *$ & $0.37^{* *}$ & $0.30 * *$ & $0.39 * *$ & $0.64 * *$ & \\
\hline 10. Open Posture & 4.91 & 0.97 & $0.57 * *$ & $0.49 * *$ & $0.51 * *$ & $0.58^{* *}$ & $0.51 * *$ & $0.65^{* *}$ & $0.69 * *$ & 0.01 & $0.37^{* *}$ \\
\hline
\end{tabular}

${ }^{*} p<0.05 ;{ }^{* *} p<0.01$. Two-tailed tests.

\section{Testing of Hypotheses 4-6}

The results from the hierarchical regression analyses provide initial support for Hypotheses 4 and Hypotheses 5, but not Hypotheses 6 (see 
Table 4a-c). Specifically, we found that the three-way interaction among perceived individualistic identity orientation, pragmatic legitimacy, and defensive posture is significantly and positively associated with the trust for the organization ( $\beta=1.90, p<0.05$ ), as predicted by Hypothesis 4 . In keeping with Hypothesis 5, we also found that the three-way interaction among perceived relational identity orientation, moral legitimacy, and tentative posture is significantly and positively associated with the trust for the organization $(\beta=1.64, p<0.1)$. Part of the two-way interactions are not significant in this models because another predictor moderates this effects. For Hypothesis 6, the three-way interaction among collectivistic identity orientation, cognitive legitimacy, and open posture is not significantly related to the trust ( $\beta=1.44$, n.s.), we cannot reject the null of Hypothesis 6.

Table 4. (a). Results of hierarchical regression analyses examining the interaction effects of individual orientation, pragmatic legitimacy, and defensive posture $(n=350)^{\text {a }}$. (b). Results of hierarchical regression analyses examining the interaction effects of relational orientation, moral legitimacy, and tentative posture $(n=350)^{\text {a }}$. (c). Results of hierarchical regression analyses examining the interaction effects of collectivistic orientation, coginitive legitimacy, and open posture $(n=350)$ a.

(a)

\begin{tabular}{|c|c|c|c|c|}
\hline \multirow{2}{*}{ Variables } & \multicolumn{4}{|c|}{ Trust } \\
\hline & (1) & (2) & (3) & (4) \\
\hline Relational identity & 0.01 & -0.05 & -0.06 & -0.07 \\
\hline Collectivistic identity & $0.13 * *$ & 0.07 & 0.07 & 0.09 \\
\hline Moral legitimacy & $0.19 * * *$ & 0.12 & 0.11 & 0.10 \\
\hline Cognitive legitimacy & 0.06 & 0.05 & 0.05 & 0.05 \\
\hline Tentative Posture & -0.02 & -0.03 & -0.03 & -0.04 \\
\hline Open Posture & $0.34^{* * *}$ & $0.32 * * *$ & $0.32 * * *$ & $0.30 * * *$ \\
\hline Individual identity & & $0.21 * * *$ & 0.06 & $0.93 * *$ \\
\hline Pragmatic legitimacy & & 0.08 & 0.18 & $0.91 * *$ \\
\hline Defensive Posture & & 0.01 & 0.11 & $0.87^{* *}$ \\
\hline Individual identity $\times$ Pragmatic legitimacy & & & 0.13 & $-1.31 *$ \\
\hline Individual identity $\times$ Defensive Posture & & & 0.11 & $-1.16 *$ \\
\hline Pragmatic legitimacy $\times$ Defensive Posture & & & -0.27 & $-1.50 * *$ \\
\hline $\begin{array}{l}\text { Individual identity } \times \text { Pragmatic legitimacy } \times \text { Defensive } \\
\text { Posture }\end{array}$ & & & & 1.90 ** \\
\hline$R 2$ & $0.39 * * *$ & $0.42 * * *$ & $0.42 * * *$ & $0.43^{* * *}$ \\
\hline$\Delta R 2$ & & $0.03^{* * *}$ & 0.00 & $0.01 * *$ \\
\hline
\end{tabular}

${ }^{a}$ Reported values are standardized regression coefficients. ${ }^{*} p<0.05 ;{ }^{* *} p<0.01 ;{ }^{* *} p<0.001$. 
Table 4. Cont.

(b)

\begin{tabular}{|c|c|c|c|c|}
\hline \multirow{2}{*}{ Variables } & \multicolumn{4}{|c|}{ Trust } \\
\hline & (1) & (2) & (3) & (4) \\
\hline Individual identity & $0.21 * *$ & $0.21 * * *$ & $0.21 * * *$ & $0.20 * * *$ \\
\hline Collectivistic identity & $0.07 * * *$ & 0.07 & 0.08 & 0.08 \\
\hline Pragmatic legitimacy & 0.11 & 0.08 & 0.08 & 0.07 \\
\hline Cognitive legitimacy & $0.06 *$ & 0.04 & 0.05 & 0.05 \\
\hline Defensive posture & -0.02 & 0.01 & 0.01 & 0.00 \\
\hline Open posture & $0.33 * * *$ & $0.32 * * *$ & $0.32 * * *$ & $0.31 * * *$ \\
\hline Relational identity & & -0.05 & -0.05 & 0.57 \\
\hline Moral legitimacy & & 0.12 & 0.01 & 0.72 \\
\hline Tentative Posture & & -0.03 & -0.07 & 0.42 \\
\hline Relational identity $\times$ Moral legitimacy & & & 0.02 & $-1.29 *$ \\
\hline Relational identity $\times$ Tentative posture & & & -0.03 & -0.96 \\
\hline Moral legitimacy $\times$ Tentative posture & & & 0.12 & -0.89 \\
\hline Relation identity $\times$ Moral legitimacy $\times$ Tentative posture & & & & $1.64 *$ \\
\hline$R 2$ & $0.42 * * *$ & $0.42 * * *$ & $0.42 * * *$ & $0.43 * * *$ \\
\hline$\Delta R 2$ & & 0.01 & 0.00 & $0.01 *$ \\
\hline
\end{tabular}

${ }^{a}$ Reported values are standardized regression coefficients. ${ }^{*} p<0.05 ;{ }^{* *} p<0.01$; ${ }^{* * *} p<0.001$.

(c)

\begin{tabular}{|c|c|c|c|c|}
\hline \multirow{2}{*}{ Variables } & \multicolumn{4}{|c|}{ Trust } \\
\hline & (1) & (2) & (3) & (4) \\
\hline Individual orientation & $0.28 * * *$ & $0.21 * * *$ & $0.23 * * *$ & $0.23 * * *$ \\
\hline Relational identity & 0.00 & -0.05 & -0.07 & -0.07 \\
\hline Pragmatic legitimacy & 0.11 & 0.08 & 0.07 & 0.07 \\
\hline Moral legitimacy & $0.28 * * *$ & 0.12 & 0.09 & 0.08 \\
\hline Defensive posture & $-0.11 *$ & 0.01 & 0.01 & 0.00 \\
\hline Tentative posture & $0.11 *$ & -0.03 & -0.01 & -0.01 \\
\hline Collectivistic identity & & 0.07 & -0.28 & 0.23 \\
\hline Coginitive legitimacy & & 0.04 & $0.71 * * *$ & $1.21 * * *$ \\
\hline Open posture & & $0.32 * * *$ & 0.33 & $0.78^{* *}$ \\
\hline Collectivistic identity $\times$ Coginitive legitimacy & & & -0.33 & $-1.32 *$ \\
\hline Collectivistic identity $\times$ Open posture & & & $0.99 * * *$ & 0.15 \\
\hline Coginitive legitimacy $\times$ Open posture & & & $-0.98 * * *$ & $-1.91 * * *$ \\
\hline Collectivistic identity $\times$ Coginitive legitimacy $\times$ Open posture & & & & 1.44 \\
\hline$R^{2}$ & $0.36^{* * *}$ & $0.42^{* * *}$ & $0.44^{* * *}$ & $0.45^{* * *}$ \\
\hline$\Delta R^{2}$ & & $0.06^{* * *}$ & $0.02^{* * *}$ & 0.00 \\
\hline
\end{tabular}

${ }^{\text {a }}$ Reported values are standardized regression coefficients. ${ }^{*} p<0.05$; ${ }^{* *} p<0.01 ;{ }^{* * *} p<0.001$.

To interpret these relationships, we plotted the three-way interactions from the models with significant effect [35]. Figure 1 shows the relationships between trust and perceived identity orientation for four illustrative conditions representing highly perceived legitimacy with 
highly perceived posture; highly perceived legitimacy with lowly perceived posture; lowly perceived legitimacy with highly perceived posture; and lowly perceived legitimacy with lowly perceived posture. We derived the slopes shown in Figure 2 from the equations reported in Table 4 and computed them from continuous data. Identity orientation was chosen for the $x$-axis because it was the most dynamic variable.

As Figure 2a illustrates, in keeping with Hypothesis 4, the consistent configuration with all high degrees of individual identity orientation, pragmatic legitimacy, and defensive posture perceptions build almost the highest trust than other configurations (except for the configuration where defensive are lowly perceived while other two attributes are perceived at high degrees). In addition, highly perceived individual identity orientation can induce absolutely higher levels of trust than lowly perceived individual identity orientation. Figure $2 \mathrm{~b}$ also partially confirm the argument in Hypothesis 5, it illustrates that the consistent configuration with all high degrees of relational identity orientation, cognitive legitimacy and tentative posture perceptions build the second highest trust (just inferior than the configuration where moral legitimacy are highly perceived while other two attributes are perceived at low degrees). In addition, highly perceived moral legitimacy can enhance trust to a higher degree than lowly perceived moral legitimacy.

(a)

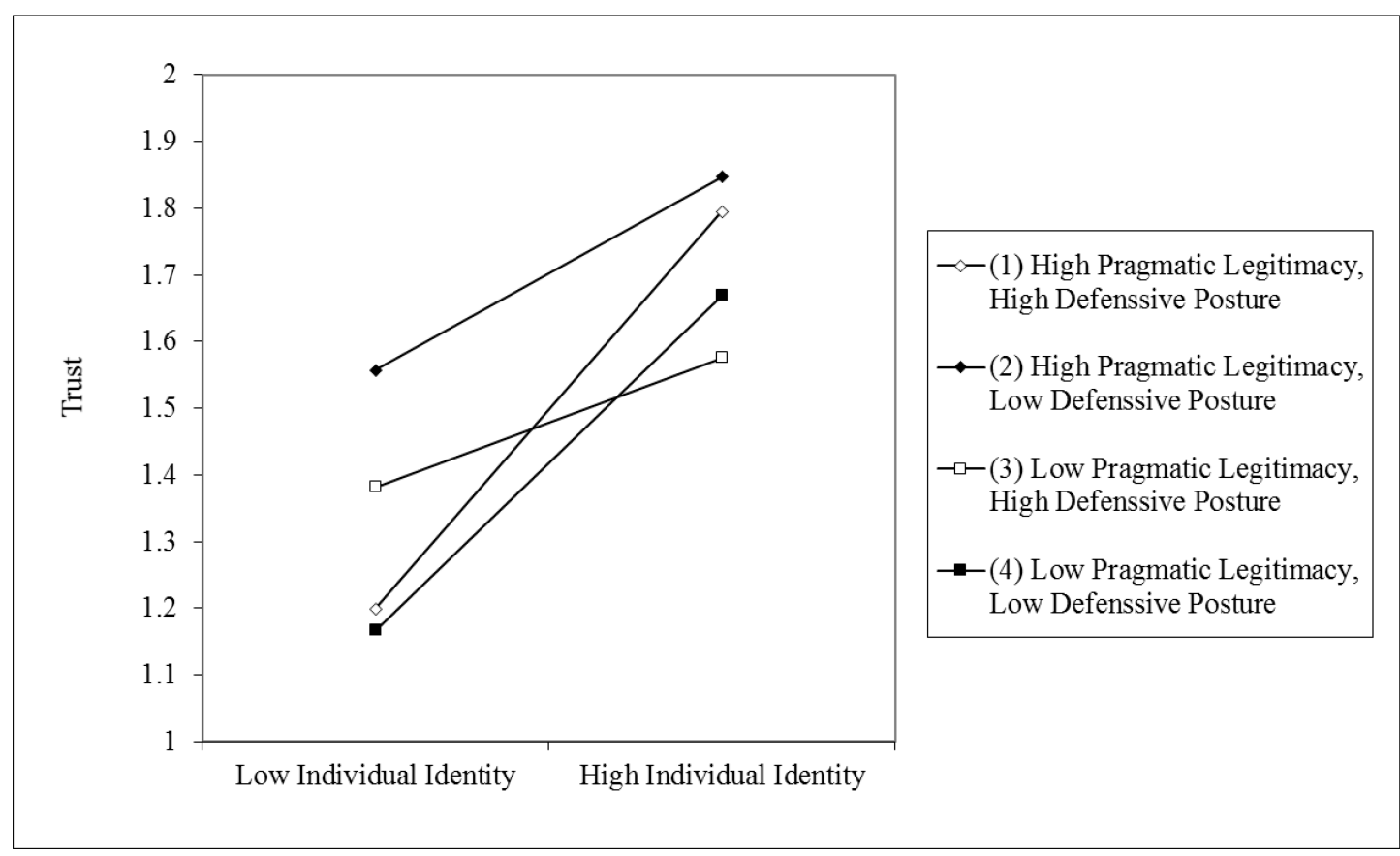

Figure 2. (a). Effects of Individual Identity Orientation, Pragmatic Legitimacy, and Defensive Posture on Trust. (b). Effects of Relational Identity Orientation, Moral Legitimacy, and Tentative Posture on Trust. 
(b)

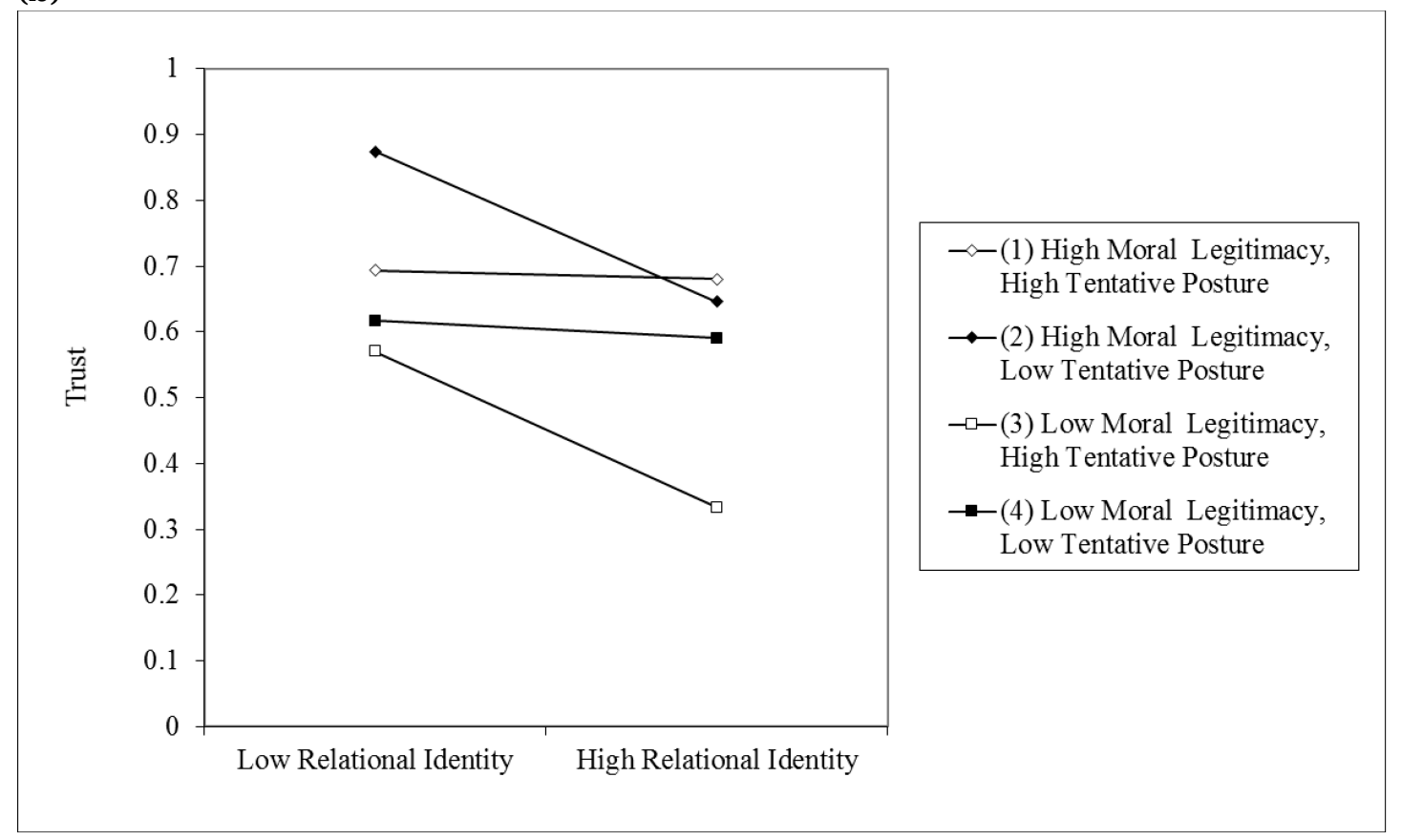

Figure 2. Cont.

\section{STUDY2: DISCUSSION}

The results of our hierarchical regression analyses in Study2 suggest that observers' trust is more strongly impacted by the perception of cognitive sensemaking attributes (identity orientation and legitimacy) and the conative sensemaking attributes (posture) together. The coherence generated by triangulating strong individual identity orientation, pragmatic legitimacy, and defensive posture generally benefits observer trust for the organization, which is the same to the coherence generated by triangulating strong relational identity orientation, cognitive legitimacy and tentative posture perceptions. However, the third configuration, perceived with collectivistic identity orientation, cognitive legitimacy, and open posture, was not empirically supported to earn trust from audiences. One plausible explanation is that the survey respondents were mostly from commercial backgrounds, where business for social good is still in the process of cognitive formulation and does not yet enjoy a taken-for-granted status.

\section{GENERAL DISCUSSION AND IMPLICATION}

In this research, we study CSR through a triangular prism of the sensemaking process, of which the dimensions involve identity orientation, legitimacy and posture. We explicitly link perceived identity orientation with perceived legitimacy, identifying a mechanism that explains how promoting both related types of identity orientation and legitimacy can be mutually reinforcing. Based on these type-by-type links, we build configurations involving the cognitive sensemaking process (identity orientation and legitimacy) and conative sensemaking process 
(posture). Our results indicate that trust is high when these three attributes are perceived consistently in one configuration. Specifically, configuration with all high degrees of individual identity orientation, pragmatic legitimacy, and defensive posture perceptions, as well as configuration with all high degrees of relational identity orientation, cognitive legitimacy and tentative posture perceptions, can enhance trust.

\section{Theoretical Contributions}

Despite the presence of skepticism towards CSR, studies on how firms can communicate CSR effectively is lacking. Although a company may act in a socially responsible manner and disseminate CSR information through official disclosure, it does not necessarily mean that a company is viewed as socially responsible [5]. Our research provides important implications that firm's inner characters, rather than the documented activities or ratings of CSR, likely matter more for observers' reactions. In contrast to content-based models of CSR, we adopt the notion of CSR as derived from organizational sensemaking processes. We identify critical dimensions of sensemaking underneath firms' CSR activities, and show how they tend to cluster together to form a coherent pattern, thus leading to a more trustworthy image of CSR. By providing a robust conceptual basis to understand how observers perceive a firm's image of sustainability, our research adds a more nuanced mechanism between CSR and observers' reaction.

CSR is often considered as advantageous to facilitate trust between the organization and its stakeholders. However, the constantly exposed instances like greenwashing and cause exploitation [4,7], as well as the rising homogeneity of CSR reporting, make CSR information seem less credible and hinder the success of CSR campaigns. The image of sustainability, if built simply by packing weakly-connected contents and activities, would be vulnerable and easily disrupted by negative events. As noted by Ring (1997), trust can be "fragile" or "resilient", and the ways of knowing employed by observers can affect the form of trust being established [36]. Beyond viewing from discrete activities, when observers become "connected" to the company's ideas, values, and objectives, they are more likely to show resilient trust and offer stable and long-term support for the focal company. Our research helps explain CSR behaviour in terms of company's inner view of what constitutes appropriate relationships with its stakeholders and of the institutional environment in which it exists. A company is more likely to be trusted in a resilient way if it could reflect a consistent and coherent pattern of intrinsic characters from various activities it conducts.

Previous researches often associate trust and sensemaking attributes independently, leading to inconsistent and sometimes contradictory findings [10,11,27]. Our study supports for a configurational approach to trust building, suggesting that scholars may need to pay greater attention to both joint and interdependent effects of performance predictors rather 
than examining them alone or in additive combination. Evaluating CSR activities may be prone to manipulation, and examining configurations of intrinsic characters could provide a more reliable basis for inferring the nature of authentic CSR engagement. Our findings suggest that firm's sensemaking attributes tend to cluster together to form a particular pattern, leading to a more recognizable image with predictable CSR outcomes.

\section{Managerial Implications}

Our research findings also have important implications for practice. Companies are often under suspicion to disseminate false or incomplete CSR information to mislead the audiences, thus it is imperative for managers to have a deeper understanding of key issues related to CSR communication. As this study indicates, CSR management should go beyond simply tallying up a list of socially responsible behaviours, and companies need to focus more on their inner view of the relationships with their stakeholders. CSR could serve as a channel for companies to articulate their intrinsic attributes, like identity, legitimacy and posture. Before arranging CSR activities, a company would better form a shared understanding of the organization's inner value, clarifying what is the organization's central and distinctive quality, how the organization associates with different stakeholders, in which way the organization choose to comply with social norms, etc. By conveying consistent and coherent intrinsic characters through CSR activities, a company can enhance the credibility of its sustainable image, and generate goodwill.

\section{Limitations and Suggestions for Future Research}

First, firm's sensemaking on CSR is a dynamic and iterative process. Our survey-based study, taking a static snapshot of stakeholder perceptions, is restricted from revealing how firm's cognitive frame of CSR adapts dynamically with the evolving environment. Despite such deficiency, our study suggests that internal consistency and coherence should be mindfully appreciated even when certain characters of CSR profile vary over time.

Second, our study was conducted using MBA students as respondents, who were not straight organizational stakeholders and might be fresh to the relative concept of CSR. This might bring risks of biased estimation in our results. Future research could refine the contexts where each CSR configuration takes effect based on the background of audiences or the sector/geography of firm.

Third, we neglected to include other variables in the sensemaking process, such as transparency related to "What firms say", consistency and commitment related to "how they behave", which were implied in the work of Basu and Palazzo (2008) [9]. We focus on three important and frequently mentioned factors (identity orientation, legitimacy, and posture), and build three ideal types of CSR configurations which were 
empirically proven to have positive influence on CSR outcomes. We provide an important analytical basis to infer the nature of authentic CSR engagement by adopting a typology-generating approach. In future research, it would be useful to go beyond three-way interactions and identify some central themes that orchestrate the alignment among a great many variables.

\section{AUTHOR CONTRIBUTIONS}

DY and RX designed the study. XC performed the two scenario experiments. RX and XC analyzed the data. RX and DY wrote the paper with input from all authors.

\section{CONFLICTS OF INTEREST}

The author declares that there is no conflict of interest.

\section{ACKNOWLEDGMENTS}

We would like to thank Insun Kim for her contribution to the design of the survey. In addition, we are grateful to GoldenBee CSR Consulting Company for recommending the sample reports of CSR.

\section{REFERENCES}

1. Vishwanathan P, van Oosterhout H, Heugens PPMAR, Duran P, van Essen M. Strategic CSR: A Concept Building Meta-Analysis. J Manage Stud. 2020;57(2):314-50.

2. Aguinis H, Glavas A. What We Know and Don't Know About Corporate Social Responsibility: A Review and Research Agenda. J Manage. 2012;38(4):932-68.

3. Cuypers IRP, Koh P-S, Wang H. Sincerity in Corporate Philanthropy, Stakeholder Perceptions and Firm Value. Organ Sci. 2015;27(1):173-88.

4. Delmas MA, Burbano VC. The Drivers of Greenwashing. Calif Manage Rev. 2011;54(1):64-87.

5. Alhouti S, Johnson CM, Holloway BB. Corporate social responsibility authenticity: Investigating its antecedents and outcomes. J Bus Res. 2015;69(3):1242-49.

6. Orlitzky M, Schmidt FL, Rynes SL. Corporate social and financial performance: A meta-analysis. Toward Integrative Corporate Citizenship. London (UK): Palgrave Macmillan; 2008.

7. Hond FD, Bakker FD, Neergaard P. Managing Corporate Social Responsibility in Action. Proc Int Assoc Bus Soc. 2007;45(1):79-80.

8. Shea CT, Hawn OV. Microfoundations of Corporate Social Responsibility and Irresponsibility. Acad Manage J. 2018;62(5):1609-42.

9. Basu K, Palazzo G. Corporate Social Responsibility: A Process Model of Sensemaking. Acad Manage Rev. 2008;33(1):122-36.

10. Burgoon JK. Relational message interpretations of touch, conversational distance, and posture. J Nonverbal Behav. 1991;15(4):233-59.

11. Cowell AJ, Stanney KM, editors. Embodiment and Interaction Guidelines for 
Designing Credible, Trustworthy Embodied Conversational Agents. In: Intelligent Agents, 4th International Workshop, IVA 2003; 2003 September 1517; Kloster Irsee, Germany. 2003.

12. Wang H, Choi J. A New Look at the Corporate Social-Financial Performance Relationship. J Manage. 2010;39(2):416-41.

13. Yoo D, Lee J. The effects of corporate social responsibility (CSR) fit and CSR consistency on company evaluation: The role of CSR support. Sustainability. 2018;10(8):2956.

14. Pratt MG, Foreman PO. Classifying Managerial Responses to Multiple Organizational Identities. Acad Manage Rev. 2000;25(1):18-42.

15. Brickson SL. Organizational identity orientation: The genesis of the role of the firm and distinct forms of social value. Acad Manage Rev. 2007;32(3):864-88.

16. Suchman MC. Managing Legitimacy: Strategic and Institutional Approaches. Acad Manage Rev. 1995;20(3):571-610.

17. Pedersen JS. In Search of Identity and Legitimation: Bridging Organizational Culture and Neoinstitutionalism. Am Behav Sci. 2006;49(7):897-907.

18. Deephouse DL. To be different, or to be the same? It's a question (and theory) of strategic balance. Strat Manage J. 1999;20(2):147-66.

19. He H, Yehuda B. Organizational Identity and Legitimacy under Major Environmental Changes: Tales of Two UK Building Societies. Br J Manage. 2010;21(1):44-62.

20. Gillespie N, Dietz G, Lockey S. Organizational Reintegration and Trust Repair after an Integrity Violation: A Case Study. Bus Ethics Q. 2014;24(03):371-410.

21. Gibbs ABW. The Double-Edge of Organizational Legitimation. Organ Sci. 1990;1(2):177-94.

22. Foreman P, David AW. Members' Identification with Multiple-Identity Organizations. Organ Sci. 2002;13(6):618-35.

23. Greenwood R, Suddaby R, Hinings CR. Theorizing Change: The Role of Professional Associations in the Transformation of Institutionalized Fields. Acad Manage J. 2002;45(1):58-80.

24. Calton JM, Payne SL. Coping With Paradox: Multistakeholder Learning Dialogue as a Pluralist Sensemaking Process for Addressing Messy Problems. Bus Soc. 2003;42(1):7-42.

25. Colquitt JA, Rodell JB. Justice, Trust, and Trustworthiness: A Longitudinal Analysis Integrating Three Theoretical Perspectives. Acad Manage J. 2011;54(6):1183-206.

26. Du S, Bhattacharya CB, Sen S. Maximizing Business Returns to Corporate Social Responsibility (CSR): The Role of CSR Communication. Int J Manage Rev. 2010;12(1):8-19.

27. Whetten K, Leserman J, Whetten R, Ostermann J, Thielman N, Swartz M, et al. Exploring Lack of Trust in Care Providers and the Government as a Barrier to Health Service Use. Am J Public Health. 2006;96(4):716-21.

28. Meyer JW, Rowan B. Institutionalized Organizations: Formal Structure as Myth and Ceremony. Am J Soc. 1977;83(2):340-63.

29. Kornberger M, Brown AD. 'Ethics' as a discursive resource for identity work. Human Relat. 2007;60(3):497-518. 
30. Carroll AB. A Three-Dimensional Conceptual Model of Corporate Performance. Acad Manage Rev. 1979;4(4):497-505.

31. George E, Chattopadhyay P, Sitkin SB, Barden J. Cognitive Underpinnings of Institutional Persistence and Change: A Framing Perspective. Acad Manage Rev. 2006;31(2):347-65.

32. Palazzo G, Scherer AG. Corporate Legitimacy as Deliberation: A Communicative Framework. J Bus Ethics. 2006;66(1):71-88.

33. Staw BM, Lance ES, Jane ED. Threat Rigidity Effects in Organizational Behavior: A Multilevel Analysis. Admin Sci Quart. 1981;26(4):501-24.

34. Zadek S. The path to corporate responsibility. Harv Bus Rev. 2004;82(12):125.

35. Cohen J, Cohen P. Applied Multiple Regression/Correlation Analysis for the Behavioral Sciences. New York (NY, US): Routledge; 2013.

36. Ring PS. Fragile and resilient trust and their roles in economic exchange. Bus Soc. 1996;35(2):148-75.

How to cite this article:

$\mathrm{Xu}$ R, Yang D, Chen X. How Can an Image of Sustainability Be Trusted? The Inner World of Corporate Social Responsibility. J Sustain Res. 2021;3(1):e210003. https://doi.org/10.20900/jsr20210003 